\title{
Patient Safety Culture as Viewed by Medical and Diagnostic Staff of Selected Tehran Hospitals, Iran
}

\author{
Majid Sabouri', Farshad Najafipour ${ }^{1}$, Mehran Jariani ${ }^{2}$, Arya Hamedanchi ${ }^{3}$, Parisa Karimi ${ }^{4 *}$ \\ ${ }^{1}$ AJA University of Medical Sciences, Tehran, Iran \\ ${ }^{2}$ NEZAJA Health and Treatment Office, Tehran, Iran \\ ${ }^{3}$ Iranian Research Center on Aging, University of Social Welfare and Rehabilitation Sciences, Tehran, Iran \\ ${ }^{4}$ Comprehensive Rehabilitation Center of Amal Charity, Tehran, Iran
}

*Corresponding Author: Parisa Karimi, M.D., Comprehensive Rehabilitation Center of Amal Charity, No:18, Shaiid Mirzaii St., Asef Ave., Zafaranieh, Tehran, Iran. Tel: +98-21-22429136, Fax: +98-21-22413069, Email: karimi.parisa@yahoo.com

Received November 3, 2016; Accepted January 11, 2017; Online Published February 28, 2017

\begin{abstract}
Background: Today, patient safety is an important issue in providing hospital services. Any failure in this area can cause undesirable consequences.

Objective: The present study evaluated the status of patient safety culture in educational hospitals of Tehran, Iran.

Methods: This cross-sectional study surveyed 205 therapeutic and diagnostic personnel of three Tehran hospitals selected using the clustered method; samples were collected in a randomized manner. To examine patient safety culture, the standard questionnaire of patient safety culture with 12 dimensions was used. Data was analyzed using SPSS software.

Results: In the 12 dimensions of patient safety culture, exchange of data, expectations, and organization management had the lowest means of $3.28( \pm 0.87)$, and $3.32( \pm 0.74)$ among the various aspects of patient safety culture. Additionally, the 2 dimensions of teamwork within the organization's units and frequency of reporting events with means of $3.71( \pm 0.79)$ and $3.73( \pm 0.7)$ had the highest means among the studied 12 dimensions of patient safety culture. The total mean of patient safety culture in the studied hospitals was $3.5( \pm 0.5)$.

Conclusion: Increasing the attention paid to patient safety culture will lead to the development and progress of hospitals in the country and will guide them toward becoming patient-friendly hospitals. Those dimensions which had low mean values in this study should be paid more attention so as to promote and protect them.

Keywords: Patient safety, Medical staff, Hospitals
\end{abstract}

\section{Background}

Today, increasing evidence reveals that a large number of patients suffer while receiving care. Injuries incurred can lead to wounds, increased duration of hospitalization, or even death. ${ }^{1}$ Since healthcare and healthcare systems have become complicated, the successful treatment of each patient requires many factors, and the probability of unintentional mistakes occurring has increased. Furthermore, a large number of health personnel (including doctors, nurses, pharmacists, and workers) are involved in the healthcare process, and this complicates the coordinated and safe care of patients unless adequate information and education are received. ${ }^{2}$ The comparison of the health sector and other sectors, including services and industry, showed that the health sector is one of the riskiest sectors, while mistakes are considered differently in this sector. In industry, systems have been designed so that mistakes are avoided or the intensity of the consequences of human mistakes are reduced; however in the health sector, the viewpoint exists that humans are perfect, and there is no room for "to err is human."

One of the simplest requests that patients can have from their doctors is to receive no injury due to mistakes or neglect during the in-hospital treatment period; however, statistics show otherwise. Based on the available evidence, about $10 \%$ of patients in other countries who are admitted to the hospital received damages in some way. Half of these injuries can be simply predicted, $6 \%$ of them cause permanent disability, and $8 \%$ cause death. ${ }^{4}$ Unsafe care and healthcare services not only impose pain on humans, they also cause heavy economic cost. In fact, it has been estimated that between $5 \%$ and $10 \%$ of costs related to health is incurred because of unsafe clinical services that can cause damages in patients. In other words, undesirable consequences of treatment cause heavy economic losses. In England, longer hospitalization due to these complications in hospitals alone imposes costs of two billion pounds. The same economic losses in the United States are estimated at \$1.7-2.9 billion because of reduced incomes, disabilities, and clinical costs. ${ }^{3}$ Uncertainty, lack of confidence, and the

Copyright (C) 2017 The Hospital Practices and Research. This is an open-access article distributed under the terms of the Creative Commons Attribution License (http://creativecommons.org/licenses/by/4.0), which permits unrestricted use, distribution, and reproduction in any medium, provided the original work is properly cited. 
satisfaction of people and related organizations should also be added to these losses. This phenomenon has influenced the world depending on the development type. ${ }^{5}$

Considering the prevalence of clinical errors, the acknowledgment of patient safety culture is important in the healthcare sector in order to change this culture and adapt it to progress in quality of care. Improving patient safety is not only a clinical issue; it is associated with the organizational dimensions. Experts believe that hospitals should develop a patient safety culture among their staff and establish structural interventions in order to increase quality and safety in healthcare. It can be said that a patient safety culture is one of the man components of promoting safety and improving the quality of patient care., ${ }^{6,7}$ The Health Department of England and the American Medical Association (AMA) have suggested that healthcare organizations should implement safe care techniques, including organizational factors such as ethical principles and feelings of safety in the workplace, environmental factors such as levels of staff and management support, teamwork factors such as teamwork and leadership, and personal factors such as self-confidence while working. ${ }^{78}$ Moreover, according to a report by the Agency for Health Care Quality Research, patient safety culture needs a correct understanding of the values, beliefs, and norms, and the most important issues for the organization are the viewpoints and behaviors implemented for the patients and which are also expected. Therefore, it is necessary for healthcare organizations to evaluate their patient safety culture to improve patient safety through healthcare processes. ${ }^{9}$ In fact, patient safety culture demonstrates the priority of patients from the viewpoint of staff in their work places and organizations. Some features are clear characteristics of such a culture, including not hiding errors or events, but revealing them; training staff in patient safety; having a reporting system for types of errors; using data from the reporting system to improve processes; reducing reprimands; teamwork; having transparent connections between sections and units and their cooperation in line with the benefits of patients; and the attention of the organization's leader to safety. ${ }^{10}$

One positive safety culture guides the behaviors of providers of health services so that patient safety becomes a priority for them and includes components such as organizational training, teamwork, feedback, non-punitive responses to errors, and cultural understanding, which are common based on the importance of safety. ${ }^{11}$

\section{Objective}

Positive safety can promote error reporting and analysis by the providers of healthcare, and that is an effective tool for improving safety. The first step toward developing a positive safety culture is to evaluate the current safety culture. Hospitals should create a patient safety culture among their staffs before implementing structural interventions; therefore, the importance of acknowledging the current patient safety culture is emphasized.

\section{Methods}

The present study is a descriptive, cross-sectional, and practical research. The study population was the medical and diagnostic staff of three selected hospitals in Tehran. In this research, sampling was conducted using the randomized-classified method, and subjects were randomly chosen from different hospital departments. Based on previous reviews, the sample size of 180 subjects was chosen with a standard deviation of $2, \alpha=.05$, and $d=0.3$. Accordingly, 70 subjects were selected from hospital A, 70 from hospital B, and 40 from hospital C; questionnaires were distributed randomly and the results were collected. Inclusion criteria for the study included employment as part of the medical staff of one of the selected centers, at least a bachelor's degree, and the subject's willingness to complete the questionnaires.

The standard Hospital Survey on Patient Safety (HSOPSC) questionnaire was used to collect the required data. This questionnaire was designed by the Agency for Health and Research Quality (AHRQ) in 2004, and it has been used to evaluate the viewpoints of medical staff regarding the patient safety culture in different parts of the world. ${ }^{13}$ HSOPSC is a reliable and valid tool which was designed based on various pieces of literature, cognitional tests, and factor analysis in order to evaluate the patient safety culture of a hospital. ${ }^{14,15}$ This questionnaire measures the acknowledgment of the staff of the patient safety culture and includes 12 dimensions. Each dimension has 3-4 questions, including frequency of reporting events (3 questions), overall understanding of patient safety (4 questions), expectations and proceedings of management for patient safety (4 questions), organizational training (4 questions), teamwork within the organizational units (4 questions), opening of connection ways (3 questions), connecting and providing feedback related to errors (3 questions), non-punitive responses to errors (3 questions), issues related to staff (4 questions), support of patient safety by management ( 3 questions), teamwork between organizational units (4 questions), and exchange and transfer of data (4 questions). It also includes 2 questions about the classification of patient safety in the sector and the number of reported events in the past 12 months.

At the end, 6 questions regarding the service unit, history of working in a hospital, history of working in the current job, time worked in one week, organizational post, and the way of interacting with patients were asked. The reliability of the questionnaire was rated as.89 by Cronbach $\alpha$.

In this questionnaire, a 5-point Likert scale was used to rate opinions in which $1=$ completely disagree and $5=$ completely agree. To obtain the score of each field, first the percentage of positive answers to questions was obtained (Those questions which had a positive meaning concept had positive answers [agree, completely agree, often agree, always agree] and the negative answers to those questions that had a negative meaning concept [disagree, completely disagree, never agree, barely agree]). If the positive answers were more than $75 \%$, the status of culture was good; if it was 
between $50 \%-75 \%$, then the cultural status was average. If it was less than $50 \%$, then the cultural status was poor.

Data was analyzed using SPSS 16 software, descriptive statistic methods (including tables, charts, central tendency index, scattering, and frequency), and the methods of presumption test (Pearson correlation coefficient, regression).

\section{Results}

As shown in Table 1, no significant difference was observed between the dimensions of frequency of reporting events, expectations, and actions of management for patient safety, organizational learning, connecting and presenting errors, problems related to staff, support of patient safety and teamwork between the organizational units by management; however, dimensions including total understanding about patient safety, teamwork within the organizational units, open connecting ways, non-punitive responses to events, and also transfer and exchange of data showed significantly different results. It should be noted that patient safety culture with the significance level (.189) was more than .05 , and the mentioned test showed no significant difference.

According to Table 2, dimensions including organizational learning, teamwork within the organizational units, nonpunitive responses to errors, and issues related to staff had no significant differences, while frequency of reporting events, total understanding of patient safety, expectations and actions of management for patient safety, open connection ways, connecting and presenting feedback about errors, support of patient safety by management, teamwork between organizational units, and the exchange

Table 1. Mean (standard deviation) of Descriptive Statistics of 12 Dimensions in Questionnaire of Studied Variables for Studied Hospitals in Tehran

\begin{tabular}{|c|c|c|c|c|c|c|}
\hline Variable & $\begin{array}{l}\text { Khanevadeh } \\
\text { Hospital }\end{array}$ & 501 Hospital & $\begin{array}{l}\text { Golestan } \\
\text { Hospital }\end{array}$ & Total & F Statistics & $\boldsymbol{P}$ \\
\hline Frequency of reporting events & $3.72( \pm 0.56)$ & $3.84( \pm 0.76)$ & $3.56( \pm 0.79)$ & $3.73( \pm 0.7)$ & 2.287 & .104 \\
\hline Total understanding of patient safety & $3.36( \pm 0.51)$ & $3.67( \pm 0.59)$ & $3.45( \pm 0.52)$ & $3.73( \pm 0.7)$ & 6.616 & .002 \\
\hline $\begin{array}{l}\text { Expectations and actions of management for } \\
\text { patient safety }\end{array}$ & $3.35( \pm 0.75)$ & $3.33( \pm 0.56)$ & $3.25( \pm 0.95)$ & $3.32( \pm 0.73)$ & .260 & .771 \\
\hline Organizational learning & $3.49( \pm 0.79)$ & $3.76( \pm 0.55)$ & $3.46( \pm 0.58)$ & $3.63( \pm 0.71)$ & 2.991 & .052 \\
\hline Teamwork within organizational units & $3.59( \pm 01.02)$ & $3.9( \pm 0.59)$ & $3.62( \pm 0.54)$ & $3.71( \pm 0.79)$ & 3.547 & .031 \\
\hline Open connection channels & $3.47( \pm 0.73)$ & $3.38( \pm 0.79)$ & $3.1( \pm 0.78)$ & $3.35( \pm 0.77)$ & 3.455 & .033 \\
\hline Connecting and presenting feedback about errors & $3.5( \pm 0.59)$ & $3.67( \pm 0.78)$ & $3.57( \pm 0.81)$ & $3.58( \pm 0.72)$ & 1.018 & .363 \\
\hline Non-punitive responses to errors & $3.47( \pm 0.84)$ & $3.83( \pm 0.7)$ & $3.86( \pm 0.73)$ & $3.7( \pm 0.78)$ & 5.743 & .004 \\
\hline Issues related to staff & $3.35( \pm 0.81)$ & $3.58( \pm 0.5)$ & $3.41( \pm 0.56)$ & $3.45( \pm 0.65)$ & 2.587 & .078 \\
\hline Management support of patient safety & $3.53( \pm 0.63)$ & $3.54( \pm 0.68)$ & $3.65( \pm 0.62)$ & $3.56( \pm 0.46)$ & .553 & .576 \\
\hline Teamwork between organizational units & $3.51( \pm 0.75)$ & $3.43( \pm 0.48)$ & $3.47( \pm 0.61)$ & $3.47( \pm 0.62)$ & .316 & .730 \\
\hline Transfer and exchange of data & $3.56( \pm 0.76)$ & $3.12( \pm 0.9)$ & $3.04( \pm 0.9)$ & $3.28( \pm 0.87)$ & 7.752 & .001 \\
\hline Patient safety culture & $3.44( \pm 0.55)$ & $3.58( \pm 0.43)$ & $3.46( \pm 0.5)$ & $3.5( \pm 0.49)$ & 1.680 & .189 \\
\hline
\end{tabular}

Table 2. Mean (Standard Deviation) of Descriptive Statistics of 12 Dimensions in Questionnaire of Variables Regarding Educational Status of Responders in the Studied Hospitals of Tehran

\begin{tabular}{lcccccc}
\hline Variables & Nurses & Doctors & Laboratory Staff & Total & F Statistics & $P$ \\
\hline Frequency of reporting events & $3.7 \pm 0.7)$ & $4.66( \pm 0.0)$ & $3.8( \pm 0.5)$ & $3.7( \pm 0.7)$ & 4.908 & .008 \\
Total understanding of patient safety & $3.4( \pm 0.56)$ & $4.25( \pm 0.0)$ & $3.87( \pm 0.13)$ & $3.5( \pm 0.56)$ & 8.371 & .000 \\
Expectations and actions of management for & $3.25( \pm 0.7)$ & $4.5( \pm 0.0)$ & $3.8( \pm 0.9)$ & $3.3( \pm 0.7)$ & 11.555 & .000 \\
patient safety & $3.6( \pm 0.7)$ & $3.66( \pm 0.0)$ & $4.1( \pm 0.5)$ & $3.6( \pm 0.7)$ & 3.785 & .024 \\
Organizational learning & $3.7( \pm 0.8)$ & $4.25( \pm 0.0)$ & $3.75( \pm 0.0)$ & $3.7( \pm 0.8)$ & 1.171 & .312 \\
Teamwork within organizational units & $3.3( \pm 0.77)$ & $4.66( \pm 0.0)$ & $3.3( \pm 0.35)$ & $3.36( \pm 0.78)$ & 7.746 & .001 \\
Open connection channels & $3.5( \pm 0.7)$ & $4.66( \pm 0.0)$ & $3.8( \pm 0.5)$ & $3.58( \pm 0.73)$ & 6.952 & .001 \\
Connecting and presenting feedback about errors & $3.7 \pm 0.8)$ & $3.66( \pm 0.0)$ & $4( \pm 0.7)$ & $3.7( \pm 0.8)$ & .910 & .404 \\
Non-punitive responses to errors & $3.4( \pm 0.7)$ & $3.75( \pm 0.0)$ & $3.37( \pm 0.13)$ & $3.4( \pm 0.66)$ & .590 & .555 \\
Issues related to staff & $3.5( \pm 0.6)$ & $5( \pm 0.0)$ & $3.67( \pm 0.35)$ & $3.56( \pm 0.65)$ & 14.484 & .000 \\
Management support of patient safety & $3.4( \pm 0.6)$ & $4.25( \pm 0.0)$ & $3.37( \pm 0.13)$ & $3.47( \pm 0.63)$ & 20.852 & .000 \\
Teamwork between organizational units & $3.2( \pm 0.87)$ & $4.75( \pm 0.0)$ & $3.75( \pm 0.26)$ & $3.28( \pm 0.87)$ & 10.113 & .000 \\
Transfer and exchange of data & $3.45( \pm 0.5)$ & $4.33( \pm 0.0)$ & $3.8( \pm 0.36)$ & $3.5( \pm 0.5)$ & 11.229 & .000 \\
Patient safety culture & & &
\end{tabular}


Table 3. Mean (Standard Deviation) of Descriptive Statistics for 12 Dimensions in the Questionnaire of Variables of the Research for Studied Departments of Selected Hospitals of Tehran

\begin{tabular}{|c|c|c|c|c|c|c|c|c|c|}
\hline Variables & Internal & Midwifery & Emergency & Surgery & $\begin{array}{l}\text { ICU-CCU- } \\
\text { NICU }\end{array}$ & $\begin{array}{l}\text { Heart and } \\
\text { Blood }\end{array}$ & Total & $\boldsymbol{F}$ & $\boldsymbol{P}$ \\
\hline $\begin{array}{l}\text { Frequency of reporting } \\
\text { events }\end{array}$ & $3.8( \pm 0.75)$ & $3.4( \pm 0.5)$ & $3.8( \pm 0.63)$ & $3.7( \pm 0.67)$ & $3.65( \pm 0.74)$ & $3.7( \pm 0.56)$ & $3.7( \pm 0.7)$ & .751 & .586 \\
\hline $\begin{array}{l}\text { Total understanding of } \\
\text { patient safety }\end{array}$ & $3.4( \pm 0.47)$ & $3.5( \pm 0.42)$ & $3.6( \pm 0.62)$ & $3.5( \pm 0.65)$ & $3.5( \pm 0.57)$ & $3.4( \pm 0.55)$ & $3.5( \pm 0.56)$ & .420 & .835 \\
\hline $\begin{array}{l}\text { Expectations and actions } \\
\text { of management for } \\
\text { patient safety }\end{array}$ & $3.4( \pm 0.82)$ & $3.3( \pm 0.47)$ & $3.4( \pm 0.62)$ & $3.1( \pm 0.63)$ & $3.4( \pm 0.74)$ & $3.3( \pm 01)$ & $3.3( \pm 0.74)$ & 1.204 & .309 \\
\hline Organizational learning & $3.5( \pm 0.66)$ & $3.7( \pm 0.57)$ & $3.9( \pm 0.5)$ & $3.7( \pm 0.75)$ & $3.7( \pm 0.69)$ & $3.1( \pm 01.1)$ & $3.6( \pm 0.7)$ & 2.287 & .047 \\
\hline $\begin{array}{l}\text { Teamwork within } \\
\text { organizational units }\end{array}$ & $3.5( \pm 0.7)$ & $3.9( \pm 0.5)$ & $4.1( \pm 0.57)$ & $3.8( \pm 0.9)$ & $3.66( \pm 0.75)$ & $3.4( \pm 01.3)$ & $3.7( \pm 0.8)$ & 2.293 & .047 \\
\hline $\begin{array}{l}\text { Open connection } \\
\text { channels }\end{array}$ & $3.4( \pm 0.6)$ & $2.7( \pm 0.8)$ & $3.4( \pm 0.8)$ & $3.4( \pm 0.8)$ & $3.2( \pm 0.8)$ & $3.5( \pm 0.8)$ & $3.3( \pm 0.77)$ & 1.528 & .183 \\
\hline $\begin{array}{l}\text { Connecting and } \\
\text { presenting feedback } \\
\text { about errors }\end{array}$ & $3.5( \pm 0.67)$ & $3.3( \pm 0.8)$ & $3.7( \pm 0.7)$ & $3.6( \pm 0.7)$ & $3.6( \pm 0.8)$ & $3.1( \pm 0.7)$ & $3.6( \pm 0.7)$ & 1.114 & .354 \\
\hline $\begin{array}{l}\text { Non-punitive responses } \\
\text { to errors }\end{array}$ & $3.7( \pm 0.8)$ & $4( \pm 0.36)$ & $3.7( \pm 0.8)$ & $3.6( \pm 0.8)$ & $3.7( \pm 0.7)$ & $3.4( \pm 01.2)$ & $3.7( \pm 0.78)$ & .403 & .846 \\
\hline Issues related to staff & $3.3( \pm 0.7)$ & $3.5( \pm 0.6)$ & $3.7( \pm 0.5)$ & $3.4( \pm 0.6)$ & $3.4( \pm 0.6)$ & $2.7( \pm 0.78)$ & $3.4( \pm 0.65)$ & 3.332 & .007 \\
\hline $\begin{array}{l}\text { Management support of } \\
\text { patient safety }\end{array}$ & $3.6( \pm 0.55)$ & $3.5( \pm 0.78)$ & $3.6( \pm 0.6)$ & $3.4( \pm 0.6)$ & $3.5( \pm 0.76)$ & $3.3( \pm 0.37)$ & $3.5( \pm 0.65)$ & .746 & .590 \\
\hline $\begin{array}{l}\text { Teamwork between } \\
\text { organizational units }\end{array}$ & $3.4( \pm 0.58)$ & $3.3( \pm 0.9)$ & $3.6( \pm 0.67)$ & $3.5( \pm 0.6)$ & $3.4( \pm 0.6)$ & $2.9( \pm 0.5)$ & $3.4( \pm 0.6)$ & 1.713 & .133 \\
\hline $\begin{array}{l}\text { Transfer and exchange } \\
\text { of data }\end{array}$ & $3.4( \pm 0.7)$ & $3( \pm 01.2)$ & $3.4( \pm 0.86)$ & $3.1( \pm 0.94)$ & $3.1( \pm 0.93)$ & $3.4( \pm 0.67)$ & $3.2( \pm 0.88)$ & 1.197 & .312 \\
\hline Patient safety culture & $3.4( \pm 0.4)$ & $3.4( \pm 0.5)$ & $3.7( \pm 0.47)$ & $3.5( \pm 0.5)$ & $3.4( \pm 0.5)$ & $3( \pm 0.5)$ & $3.5( \pm 0.5)$ & 1.693 & .138 \\
\hline
\end{tabular}

Table 4. Frequency, Percentage, and Status of Patient Safety Culture in Selected Hospitals of Tehran

\begin{tabular}{lllll}
\hline Patient Safety Culture & Number & Percentage & Real Percentage & Associated Percentage \\
\hline Poor & 7 & 3.4 & 3.6 & 65 \\
Average & 128 & 62.4 & 31.5 & 68.5 \\
Good & 62 & 48.3 & & 100 \\
Without answer & 8 & 3.9 & 100 & \\
Total & 197 & 96.1 & & \\
\hline
\end{tabular}

and transfer of data demonstrated significant differences. It should also be noted that patient safety culture with a significant level of (.0001) was less than. 05, and the mentioned test had a statistically significant difference.

As seen in Table 3, the dimensions of frequency of reporting events, total understanding of patient safety, expectations and actions of management for patient safety, open connection channels, connecting and presenting feedback about errors, non-punitive responses to errors, support of patient safety by management, teamwork between organizational units, and data transfer and exchange had no significant differences; however, the dimensions of organizational learning, teamwork within organizational units, and issues related to staff in the Emergency and Heart and Blood Departments of all groups showed significant differences. The Emergency Department had the highest score in the mentioned dimensions, while the Heart and Blood Department had the lowest score. It should be noted that patient safety culture with a significance level of .138 was more than. 05 , and the mentioned test had no statistically significant difference. Table 4 shows the status of patient safety culture in the selected hospitals of Tehran. As shown, 7 responders (3.4\%) were poor, 128 responders $(62.4 \%)$ were average, and 62 responders (48.3\%) were good. Eight subjects (3.9\%) did not answer this question.

\section{Discussion}

In order to develop a safety culture, the current dominant culture should first be evaluated accurately using an appropriate tool. The present research was conducted using a questionnaire aimed at studying patient safety culture from the viewpoint of therapeutic and detection staff of selected hospitals in Tehran. The results of this study 
revealed that, although the patient safety culture receiving the highest score was noted in Hospital B, the difference between the studied hospitals was not significant. In total, the score of the patient safety culture in the studied hospitals was not at a desirable level. Current studies in Iran also support these findings. The study of Maghri et al demonstrated that general hospitals affiliated with Tehran University of Medical Sciences do not have a good status in terms of patient safety culture. ${ }^{16}$ In most similar studies, hospitals are rated as poor in terms of observing training and research indexes based on patient safety. ${ }^{14,17}$

Considering the important role of nurses in the paradigm of patient safety culture, most global studies allocated the largest part of the sample to nurses. ${ }^{18,19}$ In the present study, too, nurses made up the main part of the sample. The results demonstrated that, in total, the level of the patient safety culture had the lowest score among nurses, while among physicians of the study population the score was significantly higher. However, considering the scores obtained in all groups, the status of the patient safety culture is evaluated as average. In a study conducted by Salavati et al on patient safety culture from the viewpoint of nurses, the dimensions of organizational learningcontinuous improvement and non-punitive responses to errors were determined by nurses to be the advantages of the patient safety culture. ${ }^{20}$ In the present study, however, nurses gave the highest scores to frequency of reporting events and non-punitive responses to errors.

Leape et $\mathrm{al}^{21}$ conducted a study at Harvard University and reported in their article entitled "The nature of unpleasant events in hospitalized patients and patient safety culture" that, among 30000 patients hospitalized in 51 hospitals of New York City, preventable errors and lack of total understanding about patient safety had led to the preventable death of 44000-98000 persons every year. Their finding was consistent with the results of the current study in that the difference in the second dimension of patient safety culture was significant.

Another study was conducted in Riyadh, Saudi Arabia in 9 general and 4 private hospitals using the AHRQ of America. ${ }^{19}$ The results showed that reporting errors system and the answering errors system, connections and leadership, and teamwork between organizational units should be promoted and improved. Another important result was that the efforts to promote patient safety in the mentioned hospitals were restricted by limited management and leadership potentials, because they were not able to develop a cultural environment through open connections and learning. The results of this study, like those of other studies conducted in this field, revealed that managers are sensitive about patient safety only when an undesirable event has occurred, because the activities related to patient safety are mostly inactive and nonpractical. Management has an incredible influence in the development and stabilization of a safety culture, learning from errors, and the encouragement of patients. The duty of the staff is also to promote safety and reduce errors in the working place; this result was consistent with the results of

\section{Research Highlights}

What Is Already Known?

Developing a patients safety culture can improve the quality of health care in hospitals.

\section{What This Study Adds?}

Exchange of data, expectations and organization management are the main dimensions of patient safety culture which have low mean values in the selected hospital in this study and should be paid more attention.

the current study.

A study conducted in Turkey entitled "Evaluation of patient safety culture in centers of primary healthcare services" with a sample volume of 212 subjects (including 44 employees providing healthcare services, 48 nurses, 51 midwives, and 27 managers). The results revealed that the level of patient safety culture was poor in the mentioned health centers ${ }^{22}$; this result was not consistent with those of the current study, because the patient safety culture was measured as average in the studied hospitals in this study.

\section{Conclusion}

This study demonstrated that, overall, patient safety culture was not at a desirable level in the selected hospitals of Tehran. These results can be generalized to all health centers. According to the systematic style of organization and the incredible effect of organizational behavior on organizational learning, teamwork within organizational units, non-punitive responses to errors, and other dimensions of patient safety culture, the accurate training and commitment to implementation of all parameters involved in improving the patient safety culture should be promoted and reinforced.

\section{Authors' Contributions}

All authors contributed substantially to the conceptualization, writing, and review of this study.

\section{Conflict of Interest Disclosures}

No conflicts of interest are declared.

\section{Ethical Approval}

In this study, the required authorization was obtained from the ethics committee and all the questionnaires were completed and analyzed in private.

\section{Acknowledgments}

This manuscript has been extracted from the MPH thesis, and all the cooperating people are acknowledged.

\section{References}

1. James JT. A new, evidence-based estimate of patient harms associated with hospital care. J Patient Saf. 2013;9(3):122-128. doi:10.1097/PTS.0b013e3182948a69.

2. Weller J, Boyd M, Cumin D. Teams, tribes and patient safety: 
overcoming barriers to effective teamwork in healthcare. Postgrad Med J. 2014;90(1061):149-154. doi:10.1136/ postgradmedj-2012-131168.

3. Makary MA, Daniel M. Medical error-the third leading cause of death in the US. BMJ. 2016;353:i2139. doi:10.1136/bmj. i2139.

4. Singh $\mathrm{H}$, Sittig DF. Advancing the science of measurement of diagnostic errors in healthcare: the Safer Dx framework. BMJ Qual Saf. 2015;24(2):103-10. doi:10.1136/bmjqs-2014-003675.

5. Thomson S, Osborn R, Squires D, Jun M. International profiles of health care systems 2012: Australia, Canada, Denmark, England, France, Germany, Iceland, Italy, Japan, the Netherlands, New Zealand, Norway, Sweden, Switzerland, and the United States. http://www.commonwealthfund.org/ /media/ Files/Publications/Fund\%20Report/2012/Nov/1645_Squires_ intl_profiles_hlt_care_systems_2012.pdf. Published 2012.

6. Schutz AL, Counte MA, Meurer S. Development of a patient safety culture measurement tool for ambulatory health care settings: analysis of content validity. Health Care Manag Sci. 2007;10(2):139-149.

7. Morello RT, Lowthian JA, Barker AL, McGinnes R, Dunt D, Brand C. Strategies for improving patient safety culture in hospitals: a systematic review. BMJ Qual Saf. 2013;22(1):1118. doi:10.1136/bmjqs-2011-000582.

8. Trzeciak S, Rivers E. Emergency department overcrowding in the United States: an emerging threat to patient safety and public health. Emerg Med J. 2003;20(5):402-405.

9. DiCuccio $\mathrm{MH}$. The relationship between patient safety culture and patient outcomes: a systematic review. J Patient Saf. 2015;11(3):135-142. doi:10.1097/PTS.0000000000000058.

10. Aiken LH, Sermeus W, Van den Heede K, et al. Patient safety, satisfaction, and quality of hospital care: cross sectional surveys of nurses and patients in 12 countries in Europe and the United States. BMJ. 2012;344:e1717. doi:10.1136/bmj.e1717.

11. Nieva $\mathrm{V}$, Sorra J. Safety culture assessment: a tool for improving patient safety in healthcare organizations. Qual Saf Health Care. 2003;12(suppl 2):ii17-ii23.

12. Sorra J, Nieva VF. Hospital survey on patient safety culture. Agency for Healthcare Research and Quality; 2004

13. Azami-Aghdash S, Azar FE, Rezapour A, Azami A, Rasi V, Klvany K. Patient safety culture in hospitals of Iran: a systematic review and meta-analysis. Med J Islam Repub Iran. 2015;29:251.

14. Salarvand S, Moayyed Kazemi A, Bahri N, et al. Assessing medical staff's view of patient safety culture. Iranian Journal of Nursing Vision. 2015;4(3):54-64.

15. Nourmoradi H, Kazemi M, Pirmoradi F, et al. Hospital Patient Safety Culture in Developing Countries: A Comparative Study in Ilam City, Iran. Br J Med Med Res. 2015;10(5):1-8.

16. Moghri J, Akbari Sari A, Rahimi Forooshani A, Arab M. Patient safety culture status in general hospitals affiliated to Tehran University of Medical Sciences (Persian). Hakim Research Journal. 2013;16(3):243-250.

17. Nasiripour AA, Jafari S. The relationship of quality improvement and patient safety with performance indicators in Shahid Beheshti University of Medical Science teaching hospitals (Persian). Journal of Payavard Salamat. 2016;10(4):311-319.

18. Hellings J, Schrooten W, Klazinga N, Vleugels A. Challenging patient safety culture: survey results. Int J Health Care Qual Assur. 2007;20(7):620-32. doi:10.1108/09526860710822752.

19. Alahmadi $\mathrm{H}$. Assessment of patient safety culture in Saudi Arabian hospitals. Qual Saf Health Care. 2010;19(5):1-5. doi:10.1136/qshc.2009.033258.

20. Salavati S, Fanoosi T, Dehghan D, Tabesh H. Nurses' perspectives on patient safety culture. Iran J Nurs. 2013;26(84):24-33.

21. Leape $L L$, Brennan TA, Laird N, et al. The nature of adverse events in hospitalized patients. Results of the Harvard Medical Practice Study II. N Engl J Med. 1991;324(6):377-384.

22. Bodur S, Filiz E. A survey on patients safety culture in primary healthcare services in Turkey. Int J Qual Health Care. 2009;21(5):348-355. doi:10.1093/intqhc/mzp035. 